\title{
Studying Summer Season Drought in Western Russia
}

\author{
Anthony R. Lupo, ${ }^{1}$ Igor I. Mokhov, ${ }^{2}$ Yury G. Chendev, ${ }^{3}$ \\ Maria G. Lebedeva, ${ }^{3}$ Mirseid Akperov, ${ }^{2}$ and Jason A. Hubbart ${ }^{1,4}$ \\ ${ }^{1}$ Department of Soil, Environmental, and Atmospheric Science, 302 E Anheuser Busch Natural Resources Building, \\ University of Missouri-Columbia, Columbia, MO 65211, USA \\ ${ }^{2}$ A.M. Obukhov Inst. of Atmospheric Physics, Russian Academy of Sciences, 3 Pyzhevsky, Moscow 119017, Russia \\ ${ }^{3}$ Natural Resources Management and Land Cadastre (Yu. Chendev), Faculty of Mining and Natural Resources Management, \\ 85 Pobeda Street Building No. 14, Floor 2, Room 2-11, Belgorod 308015, Russia \\ ${ }^{4}$ Department of Forestry, Anheuser Busch Natural Resources Building, University of Missouri-Columbia, Columbia, MO 65211, USA \\ Correspondence should be addressed to Anthony R. Lupo; lupoa@missouri.edu
}

Received 21 September 2013; Revised 18 January 2014; Accepted 21 January 2014; Published 26 February 2014

Academic Editor: Yafei Wang

Copyright (C) 2014 Anthony R. Lupo et al. This is an open access article distributed under the Creative Commons Attribution License, which permits unrestricted use, distribution, and reproduction in any medium, provided the original work is properly cited.

During the 2010 summer, a severe drought impacted Western Russia, including regions surrounding Moscow and Belgorod (about $700 \mathrm{~km}$ south of Moscow). The drought was accompanied by high temperatures. Moscow recorded $37.8^{\circ} \mathrm{C}\left(100^{\circ} \mathrm{F}\right)$ for the first time in over 130 years of record keeping. The record heat, high humidity, dry weather, and smoke from forest fires caused increased human mortality rates in the Moscow region during the summer. The excessive heat and humidity in Western Russia were the result of atmospheric blocking from June through mid-August. The NCAR-NCEP reanalyses were used to examine blocking in the Eastern European and Western Russia sector during the spring and summer seasons from 1970 to 2012 . We found that drier years were correlated with stronger and more persistent blocking during the spring and summer seasons. During these years, the Moscow region was drier in the summer and Belgorod during the spring seasons. In the Moscow region, the drier summers were correlated with transitions from El Niño to La Niña, but the opposite was true in the Belgorod region. Synoptic flow regimes were then analyzed and support the contention that dry years are associated with more blocking and El Niño transitions.

\section{Introduction}

During the summer of 2010, a severe drought impacted Western Russia, including the regions surrounding Moscow and Belgorod (about $700 \mathrm{~km}$ to the south of Moscow). The drought was accompanied by record high temperatures and humidity. Moscow recorded $37.8^{\circ} \mathrm{C}\left(100^{\circ} \mathrm{F}\right)$ for the first time in over 130 years of record keeping. The combination of heat, dry weather, and smoke from forest fires caused increased mortality rates in the Moscow region during July and August 2010, (http://ifaran.ru/science/seminars/Summer2010.html). The record temperatures and humidity in both regions were the result of strong atmospheric blocking from late June through early August (e.g., [1-9]). The result was increased human mortality, as well as more forest and peat fires (e.g., [36]). These fires were the cause of severe air quality problems in Moscow and other cities.
Several studies have examined various aspects of the summer 2010 blocking events that led to this drought. For example, $[1,3]$ linked the occurrence of these blocking events to the record high temperatures and examined these events within the context of climate variability and change. Studies $[4,5]$ examined the formation of air pollution events and the impact of these pollution events on local and regional radiation and heat budgets. Then, [6] also found that the atmospheric dynamics were more similar to that of winter season blocking events. The resulting high humidity that accompanied these blocking events and the source of this humidity was examined in [6-8]. These studies determined that the Atlantic and Mediterranean were the primary source regions of humidity. Finally, these blocking events inspired [9] to study the likelihood of future occurrences of northern hemisphere blocking episodes in a warmer climate using and atmospheric general circulation model. They found no 
tendency for more or stronger summer blocking events in two climate change scenarios.

Long range (seasonal) forecasting has been of interest to the meteorology community for about two decades (e.g., $[10,11])$. Much of the interest has been generated by the agricultural community which is increasingly sensitive to long term drought and heat stress. Thus, the ability to anticipate these conditions months in advance is of general scientific and applied interest. Within this context, [1215] examined interannual and interdecadal variability in the climate of the Midwestern United States with the goal of using this information to generate long range forecasts (http://weather.missouri.edu/gcc/). Also, [13] explored the role of blocking in the summer season climate of the Midwest and found that summer blocking in the north Pacific generally leads to cooler and wetter conditions in Missouri and the surrounding region.

These investigations supported the conclusions of [16] who provided evidence that in the Midwest region, the phase of El Niño itself was not strongly correlated with the summer season temperature and the precipitation regime. However, the change in phase of El Niño and Southern Oscillation (ENSO) was shown to be a more important indicator for the occurrence of wetter or drier summers. In particular, it was found that the time between significant rainfall events was nearly three weeks during summers that were transitioning toward La Niña or were in steady-state La Niña conditions. These summers were generally warmer as well [13-15]. Summers in which the transition was toward El Niño or steady state ENSO conditions were cooler and featured more frequent rain events. These summers were also associated with more blocking in the North Pacific [13].

ENSO is also understood to have an impact on European weather and climate including Western Russia. Western Russia, however, is known to be regularly impacted by drought and is a region where blocking is also prevalent, even during the warm season (e.g., $[17,18])$. The goals of this work were to determine whether or not blocking can be used as an indicator of drought potential and determine whether ENSO or the transition of ENSO phase may be influential in determining drought-producing flow regimes. Such a study has not been published using data within this region. In addition, synoptic flow regimes will be examined and demonstrate a distinct difference between anomalously dry and wet years in the study region.

\section{Data and Methods}

2.1. Data. The observed blocking information was obtained from the blocking archive housed in the University of Missouri Weather Analysis and Visualization (WAV) laboratory by the Global Climate Change Group (GCC) (http://weather.missouri.edu/gcc/). Precipitation and temperature data for the Moscow and Belgorod were obtained from the All Russia Research Institute of Hydrometeorological Information-World Data Centre (RIHMI-WDC) (http://meteo.ru/). The blocking information used was duration (days) and intensity (BI) and is available from
TABLE 1: A list of years examined in this study separated by ENSO phase. Each ENSO year begins in October and ends in September. The El Niño year (e.g., 1969) is defined as starting in October (1969) and ending in September (1970). ENSO definition can be found online at http://www.coaps.fsu.edu/jma.shtml.

\begin{tabular}{lcc}
\hline La Niña (LN) & Neutral (NEU) & El Niño (EN) \\
\hline $1970-1971$ & $1977-1981$ & 1972 \\
$1973-1975$ & $1983-1985$ & 1976 \\
1988 & $1992-1996$ & 1982 \\
$1998-1999$ & $2000-2001$ & $1986-1987$ \\
2007 & $2003-2005$ & 1991 \\
2010 & 2008 & 1997 \\
& $2011-2012$ & 2002 \\
& & 2009 \\
\hline
\end{tabular}

1968 to 2014 . Precipitation data was provided in millimeters. The temperature and precipitation data were obtained for the period from 1970 to 2012 .

2.2. Methods. The blocking definition used in this study can be found in [18] and references therein (and below). The blocking index is a combination of subjective and objective blocking definitions found in the previous literature and is based on the zonal index. Block intensity is a normalized center point height value and is proportional to the Northern Hemisphere height gradient and vorticity [18].

The ENSO definition used here is used in many studies (e.g., $[12,13]$ and references therein). In summary, the index classifies years as El Niño (EN), La Niña (LN), and neutral (NEU) based on 6-month running-mean Pacific Ocean basin sea surface temperature (SST) anomaly thresholds bounded by the region $5^{\circ} \mathrm{N}, 5^{\circ} \mathrm{S}, 150^{\circ} \mathrm{W}$, and $90^{\circ} \mathrm{W}$. The defined region is the Nino 3 region but encompasses part of the Nino 3.4 region $\left(170^{\circ} \mathrm{W}\right.$ to $\left.120^{\circ} \mathrm{W}\right)$ in the tropical Pacific. The anomaly thresholds used to define EN years are those greater than $+0.5^{\circ} \mathrm{C}$, less than $-0.5^{\circ} \mathrm{C}$ for LN years, and NEU otherwise. The ENSO year is defined as beginning on 1 October (Table 1) and ending on 30 September the following year (following the references above and COAPS (http://coaps.fsu.edu/)).

In this study, the spring (summer) season was defined as February through May (June-August) for the purposes of tabulating blocking events. Also, blocking events were considered to impact the region of Eastern Europe and Western Russia using the longitudes within the sector $20^{\circ} \mathrm{E}-$ $60^{\circ} \mathrm{E}$, and this includes the Moscow and Belgorod regions.

\section{Blocking and Precipitation}

The summer of 2010 was very dry in the Moscow region. The blocking dynamics of the spring and summer blocking episode from May through August were examined by [6] Figure 1 shows the mean $500 \mathrm{hPa}$ heights for the Northern Hemisphere for July 2010. The blocking event is clearly evident, even in the mean height field. Persistent blocking also impacted Eastern Russia during the summer and caused drought conditions, but this blocking event was not examined here. 
TABLE 2: Summers that were generally dry over Western Russia (Moscow and Belgorod regions). The data shown here are for the Moscow region. Normal precipitation is $126 \mathrm{~mm}, 242 \mathrm{~mm}$, and $705 \mathrm{~mm}$ for the spring, summer, and year, respectively. The number of events, days, and intensity is shown for February-August/summer months.

\begin{tabular}{lccccccc}
\hline Year & ENSO trans & Blocking events & Days & Intensity & $\begin{array}{c}\text { Spring precipitation } \\
(\mathrm{mm})\end{array}$ & $\begin{array}{c}\text { Summer precipitation } \\
(\mathrm{mm})\end{array}$ & $\begin{array}{c}\text { Annual precipitation (mm) } \\
1972\end{array}$ \\
& LA-EL & $6 / 3$ & $51 / 36$ & $3.31 / 2.68$ & 168.0 & 126.0 & 529.0 \\
1975 & LA-LA & $6 / 2$ & $39 / 14$ & $2.81 / 2.11$ & 76.0 & 245.0 & 559.0 \\
2002 & Neu-EL & $7 / 4$ & $68 / 41$ & $2.50 / 2.22$ & 60.8 & 94.8 & 540.5 \\
2003 & EL-Neu & $4 / 1$ & $57 / 32$ & $2.49 / 1.77$ & 108.3 & 291.0 & 701.2 \\
2010 & EL-LA & $6 / 3$ & $88 / 48$ & $2.46 / 2.21$ & 112.0 & 142.0 & 602.0 \\
\hline Average & & $5.8 / 2.6$ & $61 / 34$ & $2.72 / 2.27$ & 139.4 & 179.8 & 586.4 \\
\hline
\end{tabular}

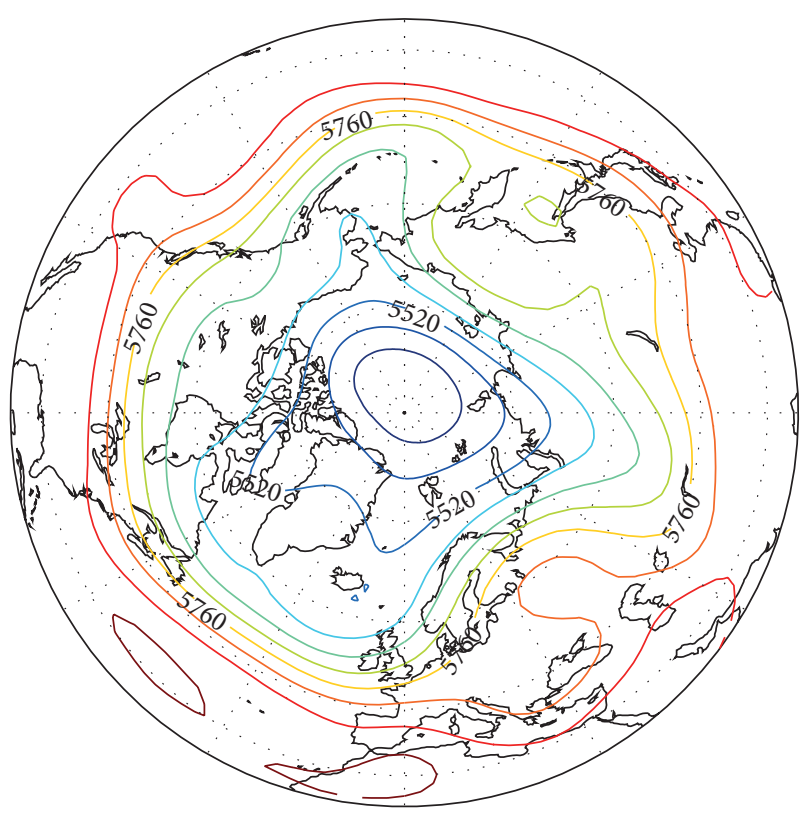

Figure 1: The mean Northern Hemisphere $500 \mathrm{hPa}$ heights $(\mathrm{m})$ for July 2010. The contour interval was $60 \mathrm{~m}$.

It was also determined by [6] that these blocking events were stronger and longer-lived than typical summer season events (about 8 days and intensity of 2.1) for this region as found in [18]. They also determined that the dynamics of the genesis and maintenance of the late spring and summer blocking events were more similar to cold season events through much of the summer in that the synoptic scale forcing was a relatively strong contributor to maintaining the block. In cold season events, the synoptic scale has been demonstrated to be a stronger contributor to maintaining blocking events ([19] and references therein).

In order to investigate the impact of blocking on the precipitation regime for the Moscow and Belgorod regions in Western Russia, five known dry summers were chosen and the numbers of blocking events during the spring and summers were then examined and presented in Table 2 for the Moscow region. The numbers of blocking days and their intensity were also calculated. These were then compared to randomly chosen summers (Table 3 ). The ENSO phase was also noted for each summer. An examination of the data demonstrated that there were more blocking events of longer duration, and these blocking events were stronger during the drought summers. These summers were also warmer than the mean $+1.5^{\circ} \mathrm{C}$, which is more than one standard deviation above the mean $\left(1.4^{\circ} \mathrm{C}\right)$. In Table 3 , these summers were wetter than normal and only slightly cooler than normal $\left(-0.8^{\circ} \mathrm{C}\right)$. Also, the preceding spring season was not necessarily drier prior to a dry summer season, which is similar to the results of the central USA and may represent a barrier between the spring and summer [16]. However, there was still increased spring blocking activity. There was no statistically significant correlation between the numbers of blocking events for all spring seasons to spring season precipitation using a simple $Z$-score test of the means (e.g., [20]). The same general conditions were true for the Belgorod region as well. Note that the dry summers with blocking involved either an ENSO phase transition or steady-state La Niña conditions, and this was true for both regions.

The results in this section indicate that spring blocking activity may be a precursor to a dry summer. A correlation analysis for the entire data set for the number of blocking events and days in the spring, summer, and the total period versus precipitation in both regions showed that the highest correlations were about -0.17 . These were significant at just under the $90 \%$ confidence level when testing the significance of the correlation coefficient [20]. The highest correlations between precipitation and blocking days were -0.24 , which was significant at the $90 \%$ confidence level. The highest correlations were between February to August blocking and summer season precipitation, as well as summer season blocking and precipitation. In testing the hypothesis above, a forecast for the summer season in the Moscow region was made for the summer of 2011 and 2012 based on frequent and persistent blocking in the $20^{\circ} \mathrm{E}-60^{\circ} \mathrm{E}$ sector during these springs. During the period, there were six blocking events (47 days), three (24) of which were summer season events. These blocking events had a mean intensity of 3.09 during the February to August period, 2.27 during the summer season. All these numbers are very comparable to the values in Table 2. The temperature was $2.8^{\circ} \mathrm{C}$ above normal in the Moscow region, a departure of more than one standard deviation, while precipitation was $71 \mathrm{~mm}$ below the normal, a departure of approximately one standard deviation. In the Belgorod region, the summer season departures were 
TABLe 3: As in Table 2 except for randomly chosen summers in the Moscow region.

\begin{tabular}{lccccccc}
\hline Year & ENSO trans & Blocking events & Days & Intensity & $\begin{array}{c}\text { Spring precipitation } \\
(\mathrm{mm})\end{array}$ & $\begin{array}{c}\text { Summer Precipitation } \\
(\mathrm{mm})\end{array}$ & Annual Precipitation (mm) \\
\hline 1978 & Neu-Neu & $3 / 0$ & $25 / 0$ & $3.38 / \mathrm{NA}$ & 213.0 & 262.0 & 788.2 \\
1984 & Neu-Neu & $6 / 1$ & $48 / 7$ & $2.65 / 1.67$ & 85.6 & 157.8 & 486.4 \\
1990 & Neu-Neu & $5 / 3$ & $39 / 22$ & $2.34 / 1.71$ & 172.7 & 165.8 & 635.6 \\
1995 & Neu-Neu & $3 / 1$ & $34 / 12$ & $2.79 / 2.07$ & 165.5 & 63.1 & 421.0 \\
2000 & Neu-Neu & $3 / 1$ & $24 / 14$ & $1.43 / 1.14$ & 148.1 & 160.3 & 506.9 \\
2004 & Neu-Neu & $4 / 4$ & $64 / 64$ & $2.43 / 2.43$ & 184.2 & 113.6 & 540.9 \\
\hline Average & & $4.0 / 1.7$ & $39 / 20$ & $2.51 / 1.97$ & 161.5 & 153.8 & 563.2 \\
\hline
\end{tabular}

in the same direction; the temperature departure was $1.7^{\circ} \mathrm{C}$ above normal (more than one standard deviation) and the precipitation $17 \mathrm{~mm}$ below the summer normal. For 2012, there was also more blocking during the February through August period but not during the summer when blocking was relatively infrequent. While temperatures were above normal $\left(+1^{\circ} \mathrm{C}\right.$ and $+2^{\circ} \mathrm{C}$ for Moscow and Belgorod, resp. $)$, the summer precipitation in each location was very close to normal. Thus, the spring blocking alone was not enough to make a forecast of a dry summer. As implied by the correlations, blocking occurrences alone may not be sufficient to make a projection, but additional information may be needed.

\section{ENSO and Precipitation}

In the previous section, it is evident that there may be a relationship between the frequency, duration, and intensity of spring and summer blocking and the climatological character of the summer season in Western Russia. In order to determine whether or not there is a relationship between the summer season precipitation regime and the phase of ENSO or the transition in ENSO phase, the data were stratified by ENSO year.

In Figure 2, all years were classified by ENSO phase and spring and summer precipitation amount was examined for both Moscow and Belgorod. In is apparent that there are no statistically significant differences using a $Z$-score test of the means (at the $90 \%$ confidence level [20]) between spring or summer season precipitation across each phase. However, in the Moscow region, summers following El Niño were the driest, while in the Belgorod region, summers following $\mathrm{La}$ Niña were the most arid. This result is similar to that shown in $[14,16]$ for the central USA. These studies found that it was the transition between ENSO phases that was the most important indicator for the summer season weather regime. They also showed that the preceding spring weather regime offered no guidance for the summer season precipitation in any region across the central USA.

In Figure 3, the data were stratified by transitions from warmer ENSO to cooler, and vice versa, as well as steady state ENSO phase. For the Moscow region, drier summers were associated with the transitions from El Niño to La Niña and during steady state La Niña conditions. In this region, Figure 3 implies that the drier summers are characterized by early summer (June and July) dryness. This result is

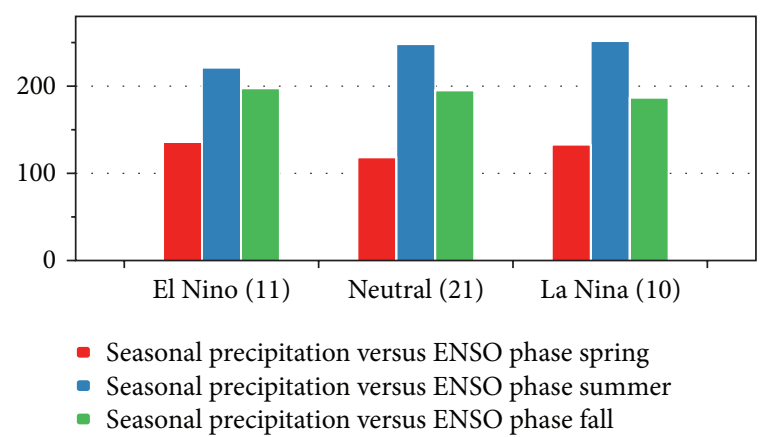

(a)

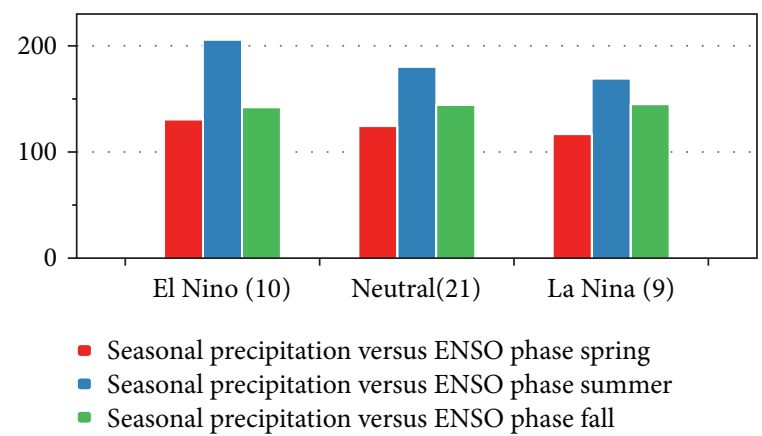

(b)

FIGURE 2: Seasonal precipitation over Western Russia for the region of Moscow (a) and Belgorod (b), separated by ENSO phase.

similar to that for the Midwestern USA, which includes the Missouri region. Steady El Niño conditions also were associated with a dry summer season; however, there was only one occurrence in this category. Therefore, for the purposes of this study the single occurrence was binned with the steady La Niña conditions. By a majority, in the cases where the ENSO phase was steady, the preceding spring seasons were dry (not shown). Additionally, the summer of 2010 was a transition year from El Niño to La Niña, while the summer of 2011 followed a La Niña year but by fall was considered a Neutral year (but colder SSTs). Thus, when combined with the blocking occurrences, the projection for the summer of 2011 verified well. For the summer of 2012, the fact that the ENSO phase remained neutral suggested a wetter summer (Table 3 ). Conversely, the increased frequency of spring blocking may 
TABLE 4: ENSO phase versus blocking (events/days) for the February-August, the presummer, and summer periods for 1970-2012.

\begin{tabular}{lccc}
\hline ENSO phase & Feb.-Aug. blocking & Feb.-May blocking & June-Aug. blocking \\
\hline El Niño & $4.8 / 45$ & $2.7 / 21$ & $2.1 / 24$ \\
Neutral & $4.1 / 43$ & $2.2 / 26$ & $1.9 / 17$ \\
La Niña & 4.8 & $2.6 / 18$ & 2.220 \\
\hline
\end{tabular}

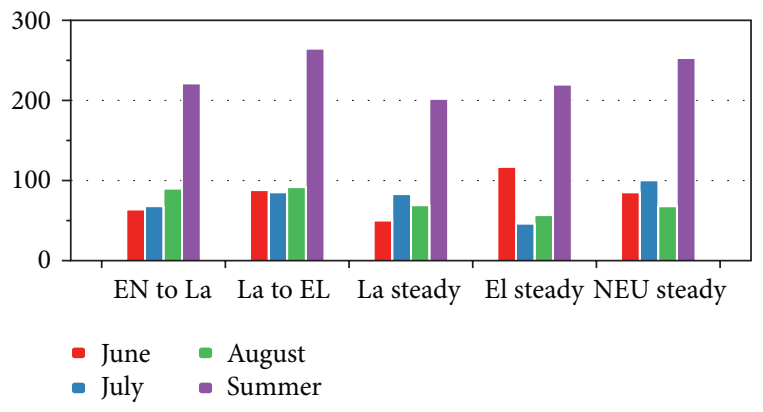

(a)

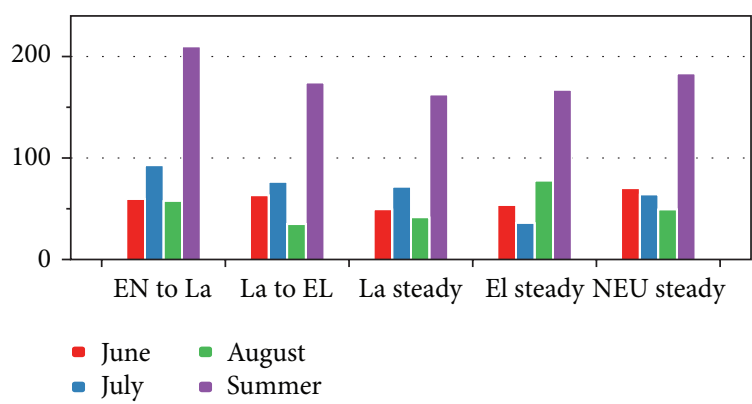

(b)

FIGURE 3: Monthly and summer precipitation for western Russia in Moscow (a) and Belgorod (b), separated by ENSO transitions from cooler to warmer, warmer to cooler, and then steady state La Niña, El Niño, and neutral conditions.

have suggested a drier summer. The blocking regime did not persist and precipitation values were close to normal. Thus, for 2011, the ENSO regime and blocking regime both pointed toward a dry summer, while in 2012 only the blocking did.

In the Belgorod region, drier summers were found to occur under similar conditions to those in the Moscow region, with one exception. In the Belgorod region, drier summers occurred with the transition from La Niña to El Niño and the later portion of the summer is drier (August). A dry late summer and fall are consistent with another published study for this region [21]. As in the Moscow region, only during steady state La Niña conditions, was the previous spring an indicator for a dry summer. While none of the results are statistically significant (at the $90 \%$ confidence level) using a $Z$-score test of the means due to the small samples here ( 43 years), the next section will examine synoptic flow regimes during these periods in order to compare them with the statistical results found in thus far.

A spectral analysis (Figure 4) provides supporting evidence of a link between blocking, ENSO, and precipitation in the Western Russia region. Figure 4(a) shows a periodogram with spectral power (ordinate) versus period in cycles per decade (abscissa) for blocking occurrences. There is a statistically significant (at the $90 \%$ confidence level (e.g., [22])) peak close to 2.5 cycles per decade (four years) which is within the 2-7 year period often used to describe ENSO. Figure 4(b) is the same as Figure 4(a), except for precipitation and there is a very strong spectral peak near four years per cycle. Finally, Figure 4(c) shows the covariance (see [22]) between blocking and precipitation when the two spectra are convolved. Here, there is also a significant peak near 2.5 cycles per decade, and similar results were found using the Belgorod region data (not shown). These results suggest a relationship between ENSO, precipitation, and blocking. Wavelet analysis could not be used here as the dataset was too small/short in duration. This type of analysis can be performed more effectively with longer data sets.

Tables 2 and 3 examine blocking occurrences and associate these with the transition of the ENSO phase. Table 4 examines further whether or not there is a relationship between blocking occurrences and ENSO itself during the February through August period from 1970 to 2012 as suggested by Figure 4 . For the whole period, there are about five blocking events per year that occur in the study region during both El Niño and La Niña years. This is one more event than during Neutral years. An examination of the number of blocking days shows that there are about seven fewer days during La Niña years in the study region over the period of study. While these results are not statistically significant at the $90 \%$ confidence level when testing the means owing in part to the small sample size, some of these results are consistent with the synoptic regimes studied in the next section. For example, years in which the phase remained neutral showed a tendency toward wetter summers and more zonal flow. In these years, there was an average of seven fewer blocking days per summer. Additionally, while our study did not look at fall season precipitation regimes [21] demonstrates that there is more blocking in late summer and fall (August-November) during drier years within this general region as well.

\section{Synoptic Analysis and Discussion}

In order to determine whether the results of the statistical analysis above reflected different flow regimes, synoptic maps were examined. Figure 5(a) shows the composite $500 \mathrm{hPa}$ heights for the five summer seasons used in Table 2. There is a distinct split flow pattern which is likely the result of a greater number of more persistent and stronger blocking events. The jet stream flows north over Scandinavia, and there is a strong height gradient across North Africa and the Middle East. Figure 5(b) shows the height anomalies which were calculated by subtracting the 1981-2010 mean $500 \mathrm{hPa}$ heights. A region of anomalously strong high pressure is 


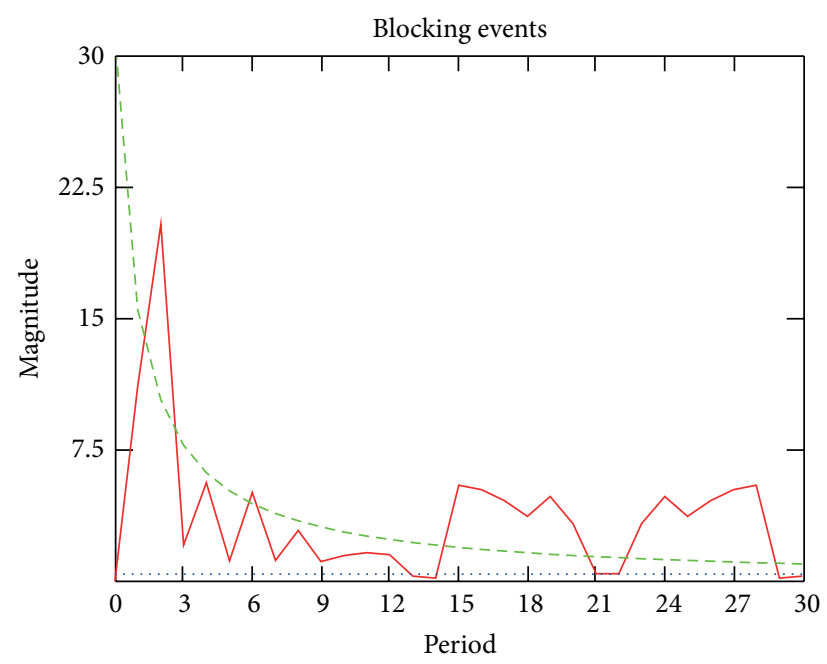

(a)

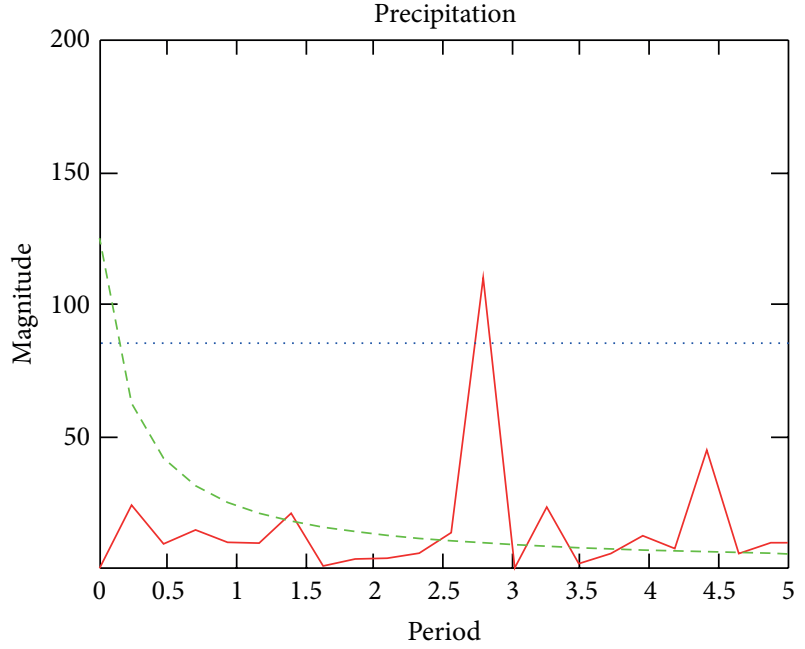

(b)

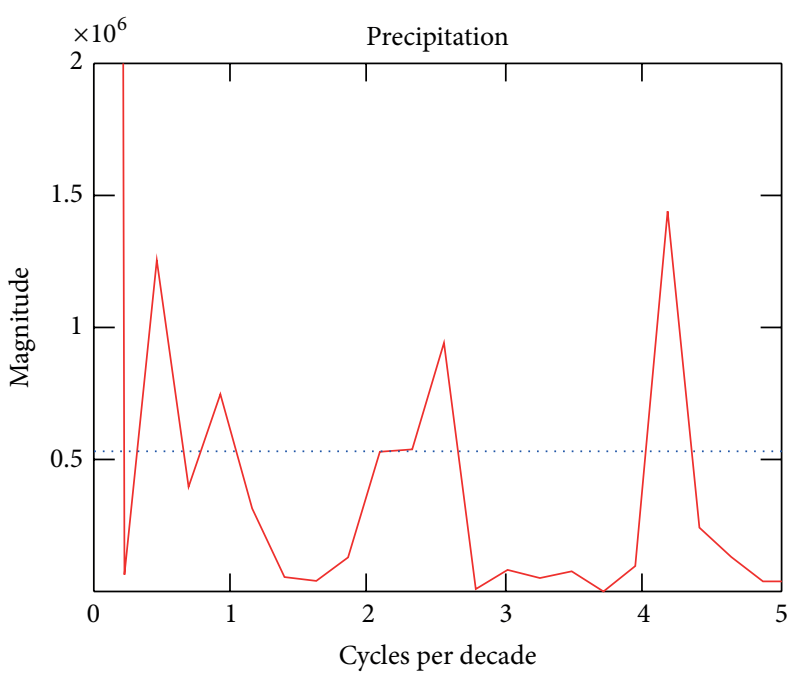

(c)

FIGURE 4: The periodograms for (a) blocking event occurrences, (b) precipitation, and (c) the cross-spectra of blocking and precipitation for the Moscow region covering the period 1970-2013. The abscissa is cycles per decade in (a), (b), and (c). The green (blue) line is the 90\% confidence level for a red (white) noise process. The dotted line in (c) assumes only a white noise process.

present over northeastern Europe and Western Russia region west of the Urals, and thus drier conditions are implied. This region of strong positive $500 \mathrm{hPa}$ height anomalies is about one standard deviation greater than the long term mean in this region (e.g., $[1,23,24])$. A similar pattern of anticyclonic height anomalies can be associated with drought in the central USA [15]. More study would be needed in order to determine the role that surface processes and other variables may have played in establishing this pattern, but such a study is beyond the scope of this study. Nonetheless, Figure 5(a) strongly supports the statistical associations found in sections three and four.

Figure 6 shows the composite $500 \mathrm{hPa}$ height maps for the summer seasons chosen at random used in Table 3. Many of these springs and summers were associated with above normal precipitation in the Moscow region. In Figure 6(a), the $500 \mathrm{hPa}$ summer flow regime over Europe and much of Russia is more zonal than that shown in Figure 5(a). In Figure 6(a) there is even a weak trough over western Russia. Figure 6(b) shows weak negative $500 \mathrm{hPa}$ height anomalies over the study region. These anomalies were less than one standard deviation below the normal but suggest a very different summer flow regime from that found in Figure 5(a).

The results above are based on comparing summer flow regimes to Moscow summer season precipitation. Thus, five of the six driest summers based on the Belgorod precipitation record were chosen in order to examine this summer season flow regime. These summers were 1994, 1996, 2008, 2009, and 2010, and were on average $+1.1^{\circ} \mathrm{C}$ above the mean summer temperature. Many of these years were associated with frequent blocking occurrences (number and days) in the study region in both the spring and summer seasons. 


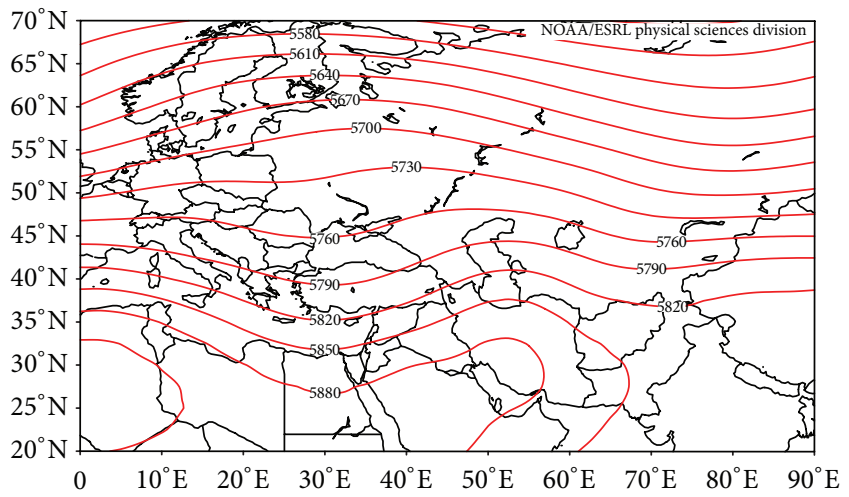

(a)

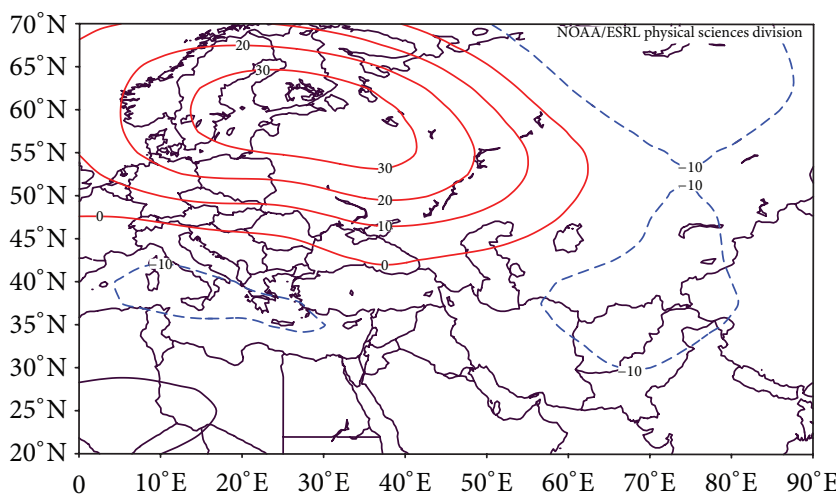

(b)

Figure 5: The composite height fields for the years given in Table 2 for the $500 \mathrm{hPa}$ level in $\mathrm{m}$ (contoured every $60 \mathrm{~m}$ ) (a) and the $500 \mathrm{hPa}$ height anomalies in $\mathrm{m}$ (contoured every $10 \mathrm{~m}$ ) (b). In (b), solid (dashed) lines are positive (negative) height anomalies.

These represented a mixture of ENSO phase and ENSO phase transitions in this group, but were generally transitioning toward a warmer ENSO phase, consistent with Table 3. Figures 7(a) and 7(b) show the composite $500 \mathrm{hPa}$ heights and anomalies over the region. There is clearly a positive $500 \mathrm{hPa}$ height anomaly associated with these summers, although it is weaker (about one-half to one standard deviation above the mean), and located further equator ward than the positive $500 \mathrm{hPa}$ height anomaly in Figure 5 . The center of the $500 \mathrm{hPa}$ height anomaly was located nearly over the Belgorod region, suggesting the suppression of precipitation formation here.

Finally, five of the six wettest summers in Belgorod were chosen for a one more $500 \mathrm{hPa}$ height composite (Figures 8(a) and 8(b)), and these were 1973, 1978, 1980, 1989, and 1997. These summers were on average $-1.3^{\circ} \mathrm{C}$ below the mean summer temperature. This composite shows strong negative height anomalies (about one standard deviation) centered over Eastern Europe and Western Russia. This negative $500 \mathrm{hPa}$ anomaly is stronger than that shown in Figure 6(b) and slightly more equator ward. Figure 8(a) suggests a split jet maximum, but for most of these years there was little blocking in the study region including no blocking at all during February to August 1997. These years also included that the ENSO phase transitions were similar to those suggested in Section 4 for wetter years.

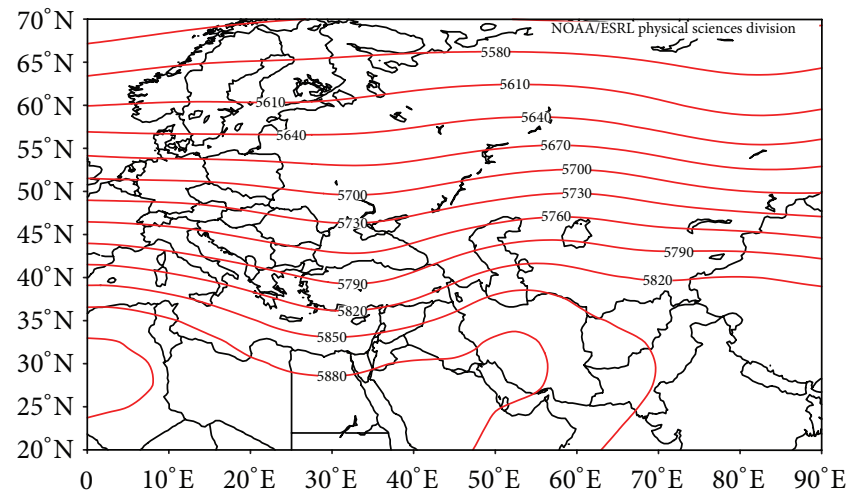

(a)

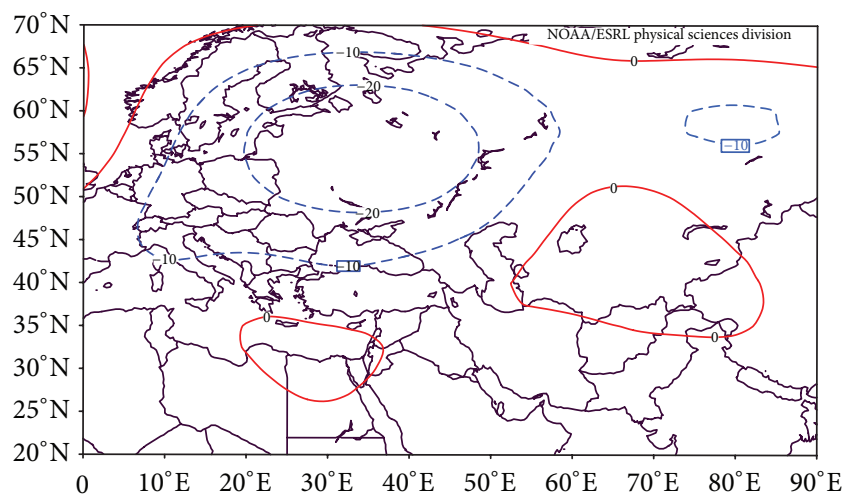

(b)

FIgURE 6: As in Figure 5, except for the summers in Table 3.

\section{Summary and Conclusions}

In response to the Russian summer drought of 2010, which brought record high temperatures and increased human mortality rates to Moscow and surrounding regions, the summer seasons (1970-2012) were examined in order to better understand the impacts of drought, the link to blocking and ENSO and improve the predictability of future extreme events. In this study, the NCAR-NCEP reanalyses were used to identify blocking, while data for the precipitation analysis were provided through RIHMI-WDC.

The preceding spring seasons for dry summers were examined and it was found that dry summers were not necessarily preceded by dry springs, which is similar to that in the central USA. However, dry summers were preceded by more active blocking in the study region during the spring seasons. These blocking events were also more persistent and stronger than events preceding normal or wetter summers. During dry summers strong blocking persisted through the season. Thus indicated that blocking is a variable that can be used to indicate the upcoming summer precipitation regime but was not itself a sufficient variable.

Much drier summers were not necessarily correlated with the phase of ENSO. Nonetheless, as was found for the Missouri region in the USA, drier summers were favored for the Moscow and Belgorod regions during steady-state 


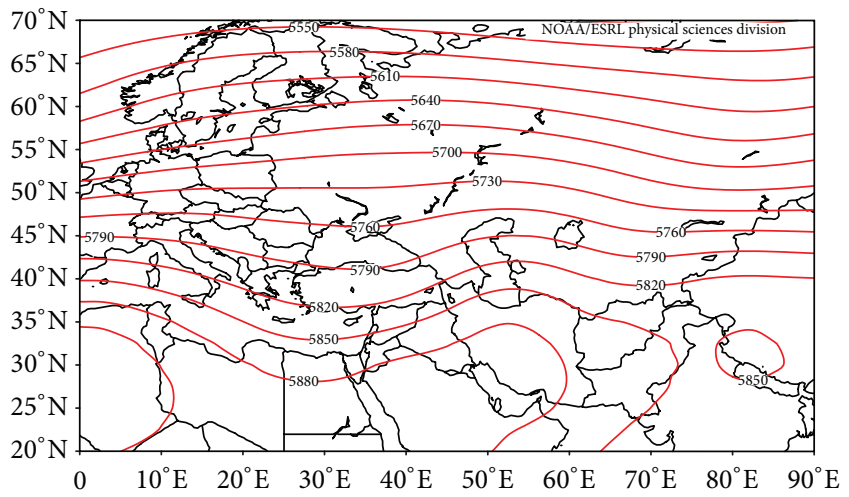

(a)

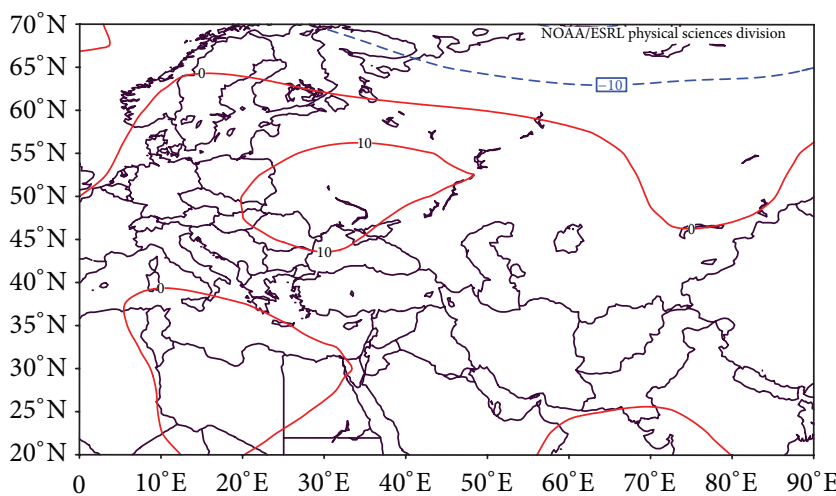

(b)

Figure 7: As in Figure 5, except for the summers of 1994, 1996, 2008, 2009, and 2010.

La Niña conditions overall and the Moscow region during transitions toward La Niña. For Belgorod, the transition toward El Niño was more important and associated with drier conditions. Thus, an ENSO phase transition (" $d-(\mathrm{EN}) / d t$ ") during the summer could be used in conjunction with blocking as an important drought indicator. This result is new in the literature, especially in applying the concept to eastern European and Western Russia summer flow regimes. Finally, a dry spring was a good indicator of summer dryness only for steady state La Niña conditions. A forecast for the 2011 summer season based on 1970-2010 data was successful in using blocking and ENSO phase as an indicator for summer season conditions, while a forecast for 2012 yielded mixed results.

As these data sets were small and did not produce statistically significant results consistently. Some tests showed statistical significance but others did not rise to the $90 \%$ confidence level, even if there was a correlation. However, seasonal forecasts or projections can still be made using contingency probabilities which is a long-range forecasting technique. Also, an examination of the $500 \mathrm{hPa}$ synoptic composites supported the statistical analysis shown here. For both dry and wet summers in Moscow and Belgorod, a very different $500 \mathrm{hPa}$ flow regime was suggested in each case. Strong tropospheric ridging dominated for dry summers, and more zonal flow or troughing over the region during moist summers. Dry summers in the Moscow region were

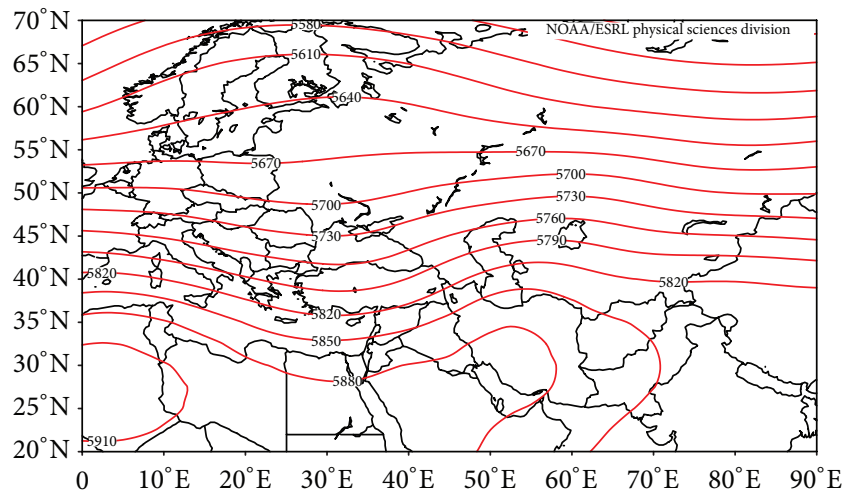

(a)

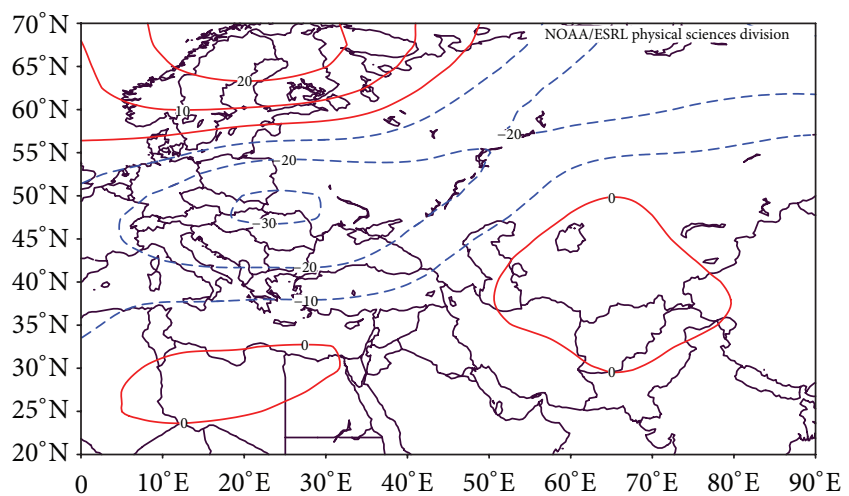

(b)

Figure 8: As in Figure 5, except for the summers of 1973, 1978, 1980, 1989, and 1997.

associated with anticyclonic $500 \mathrm{hPa}$ height anomalies centered over the poleward portion of the study region, while the randomly chosen wetter summers were associated with weaker troughing. A similar result was obtained using some of the driest and wettest summers for the Belgorod region, but the $500 \mathrm{hPa}$ height anomalies were located further equator ward.

\section{Conflict of Interests}

The authors declare that there is no conflict of interests regarding the publication of this paper.

\section{Acknowledgments}

The authors would like to thank the reviewers for their comments which helped to make this work stronger. They would also like to thank the editor for handling this paper. This work was partially supported under a NIFA Grant, Project no. MO-NRSL0752.

\section{References}

[1] R. Dole, M. Hoerling, J. Perlwitz et al., "Was there a basis for anticipating the 2010 Russian heat wave?" Geophysical Research Letters, vol. 38, no. 6, Article ID L06702, 5 pages, 2011. 
[2] M. Matsueda, "Predictability of Euro-Russian blocking in summer of 2010," Geophysical Research Letters, vol. 38, no. 6, Article ID L06801, 6 pages, 2011.

[3] I. I. Mokhov, "Specific features of the 2010 summer heat formation in the European territory of Russia in the context of general climate changes and climate anomalies," Izvestiya, Atmospheric and Oceanic Physics, vol. 47, no. 6, pp. 653-660, 2011.

[4] N. F. Elansky, I. I. Mokhov, I. B. Belikov et al., "Gaseous admixtures in the atmosphere over Moscow during the 2010 summer," Izvestiya, Atmospheric and Oceanic Physics, vol. 47, no. 6, pp. 672-681, 2011.

[5] I. A. Gorchakova and I. I. Mokhov, "The radiative and thermal effecta of smoke aerosol over the region of Moscow during the summer fires of 2010," Izvestiya, Atmospheric and Oceanic Physics, vol. 48, no. 5, pp. 496-503, 2012.

[6] A. R. Lupo, I. I. Mokhov, M. G. Akperov, A. V. Chernokulsky, and H. Athar, "A dynamic analysis of the role of the planetary and synoptic scale in the summer of 2010 blocking episodes over the European part of Russia," Advances in Meteorology, vol. 2012, Article ID 584257, 11 pages, 2012.

[7] S. A. Sitnov and I. I. Mokhov, "Peculiarities of water vapor distribution in the atmosphere over the European part of Russia in summer 2010," Doklady Earth Sciences, vol. 448, no. 1, pp. 8691, 2013.

[8] S. A. Sitnov and I. I. Mokhov, "Water vapor content in the atmosphere over European Russia during the summer 2010 fires," Izvestiya, Atmospheric and Oceanic Physics, vol. 49, no. 4, pp. 380-394, 2013.

[9] I. I. Mokhov, M. G. Akperov, M. A. Prokofyeva, A. V. Timazhev, A. R. Lupo, and H. le Treut, "Blockings in the Northern hemisphere and Euro-Atlantic region: estimates of changes from reanalysis data and model simulations," Doklady Earth Sciences, vol. 449, no. 2, pp. 430-433, 2013.

[10] A. G. Barnston, H. M. van den Dool, D. R. Rodenhuis et al., "Long-lead seasonal forecasts-where do we stand?" Bulletin of the American Meteorological Society, vol. 75, no. 11, pp. 20972114, 1994.

[11] J. Anderson, H. van den Dool, A. Barnston, W. Chen, W. Stern, and J. Ploshay, "Present-day capabilities of numerical and statistical models for atmospheric extratropical seasonal simulation and prediction," Bulletin of the American Meteorological Society, vol. 80, no. 7, pp. 1349-1362, 1999.

[12] A. R. Lupo, E. P. Kelsey, D. K. Weitlich et al., "Interannual and interdecadal variability in the predominant Pacific region SST anomaly patterns and their impact on climate in the midMississippi valley region," Atmosfera, vol. 20, no. 2, pp. 171-196, 2007.

[13] A. R. Lupo, E. P. Kelsey, D. K. Weitlich, N. A. Davis, and P. S. Market, "Using the monthly classification of global SSTs and 500 $\mathrm{hPa}$ height anomalies to predict temperature and precipitation regimes one to two seasons in advance for the mid-Mississippi region," National Weather Digest, vol. 32, pp. 11-33, 2008.

[14] K. Birk, A. R. Lupo, P. Guinan, and C. E. Barbieri, “The interannual variability of midwestern temperatures and precipitation as related to the ENSO and PDO," Atmosfera, vol. 23, no. 2, pp. 95-128, 2010.

[15] A. R. Lupo, N. B. Smith, P. E. Guinan, and M. D. Chesser, "The long-term climatology of the Missouri region dew points and the implications for regional climate and human comfort," National Weather Digest, vol. 35, pp. 81-92, 2012.
[16] C. W. Ratley, A. R. Lupo, and M. A. Baxter, "Determining the spring to summer transition in the missouri ozarks using synoptic scale atmospheric data," Transactions to the Missouri Academy of Sciences, vol. 36, pp. 69-76, 2002.

[17] G. M. Agayan and I. I. Mokhov, "Quasistationary autumn regimes of the Northern Hemisphere atmosphere in FGGE," Izvestiya, Atmospheric and Oceanic Physics, vol. 25, pp. 11501156, 1989.

[18] J. M. Wiedenmann, A. R. Lupo, I. I. Mokhov, and E. A. Tikhonova, "The climatology of blocking anticyclones for the Northern and Southern Hemispheres: block intensity as a diagnostic," Journal of Climate, vol. 15, no. 23, pp. 3459-3473, 2002.

[19] H. Athar and A. R. Lupo, "Scale and stability analysis of blocking events from 2002-2004: a case study of an unusually persistent blocking event leading to a heat wave in the Gulf of Alaska during August 2004," Advances in Meteorology, vol. 2010, Article ID 610263, 15 pages, 2010.

[20] J. Neter, W. Wasserman, and G. A. Whitmore, Applied Statistics, Allyn \& Bacon, Boston, Mass, USA, 3rd edition, 1988.

[21] I. G. Semenova, "Regional atmospheric blocking in the drought periods in Ukraine," Journal of Earth Science and Engineering, vol. 3, pp. 341-348, 2013.

[22] D. S. Wilks, Statistical Methods in the Atmospheric Sciences, vol. 91 of International Geophysics, Academic Press, New York, NY, USA, 2nd edition, 2006.

[23] A. Dell'Aquila, V. Lucarini, P. M. Ruti, and S. Calmanti, "Hayashi spectra of the northern hemisphere mid-latitude atmospheric variability in the NCEP-NCAR and ECMWF reanalyses," Climate Dynamics, vol. 25, no. 6, pp. 639-652, 2005.

[24] J. W. Hurrell, H. van Loon, and D. J. Shea, "The mean state of the troposphere," NCAR Tech Memo \#NCAR/CAS/95-08, 1995. 

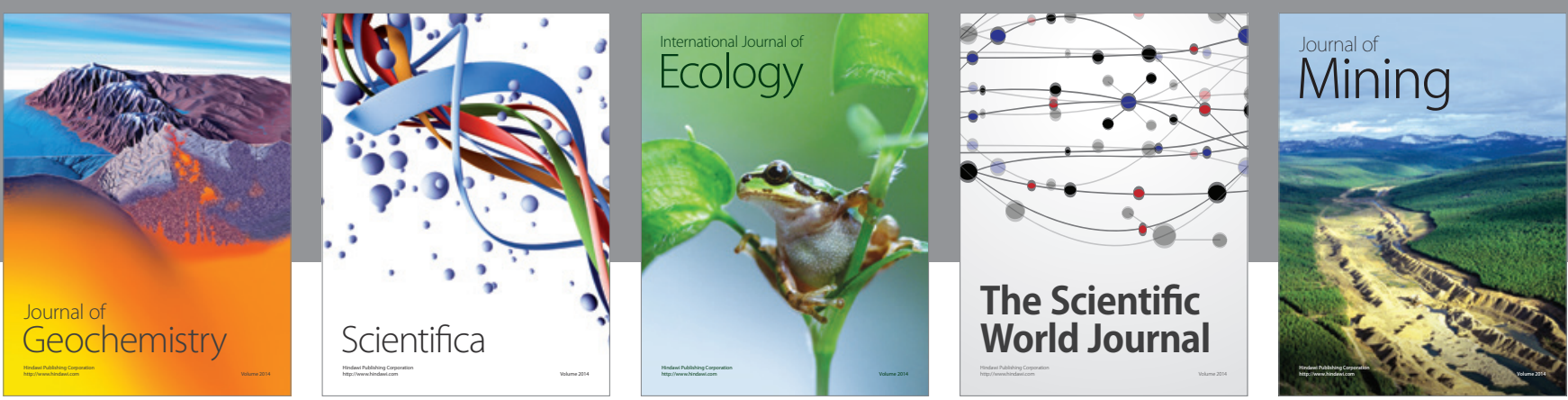

The Scientific World Journal
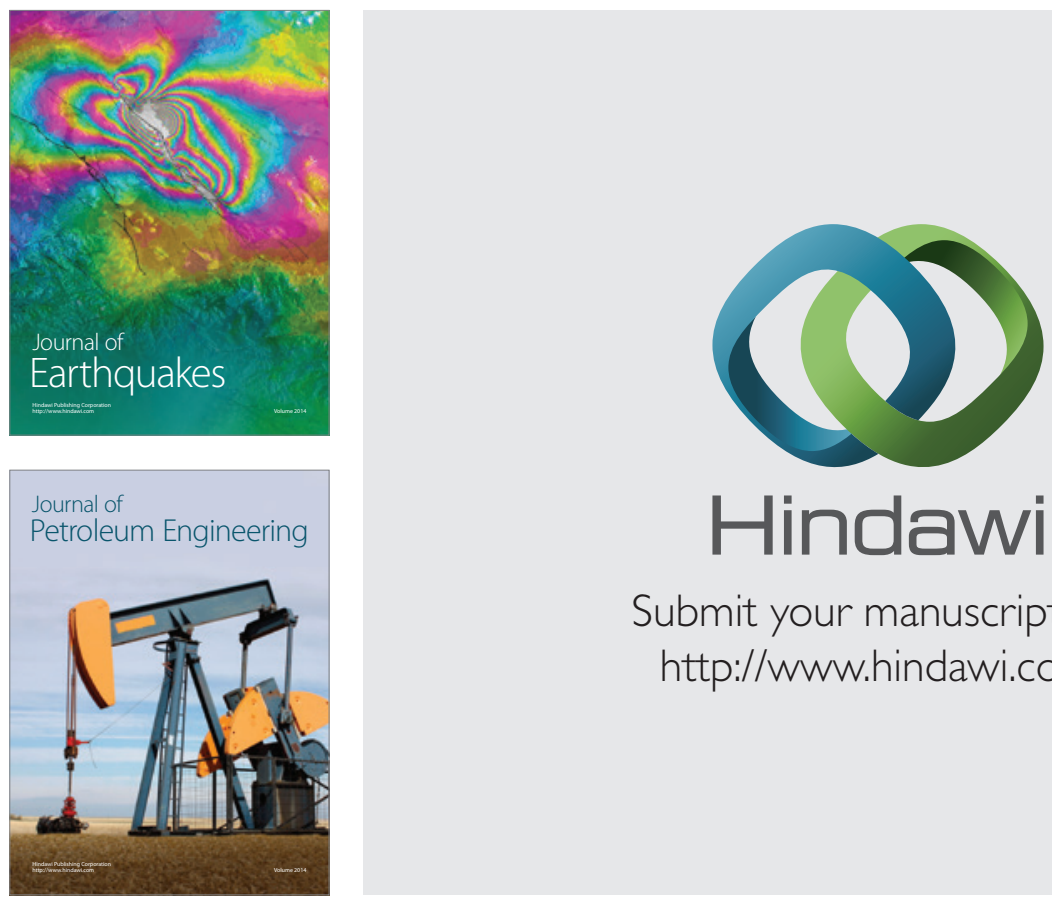

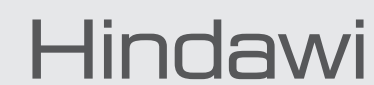

Submit your manuscripts at

http://www.hindawi.com
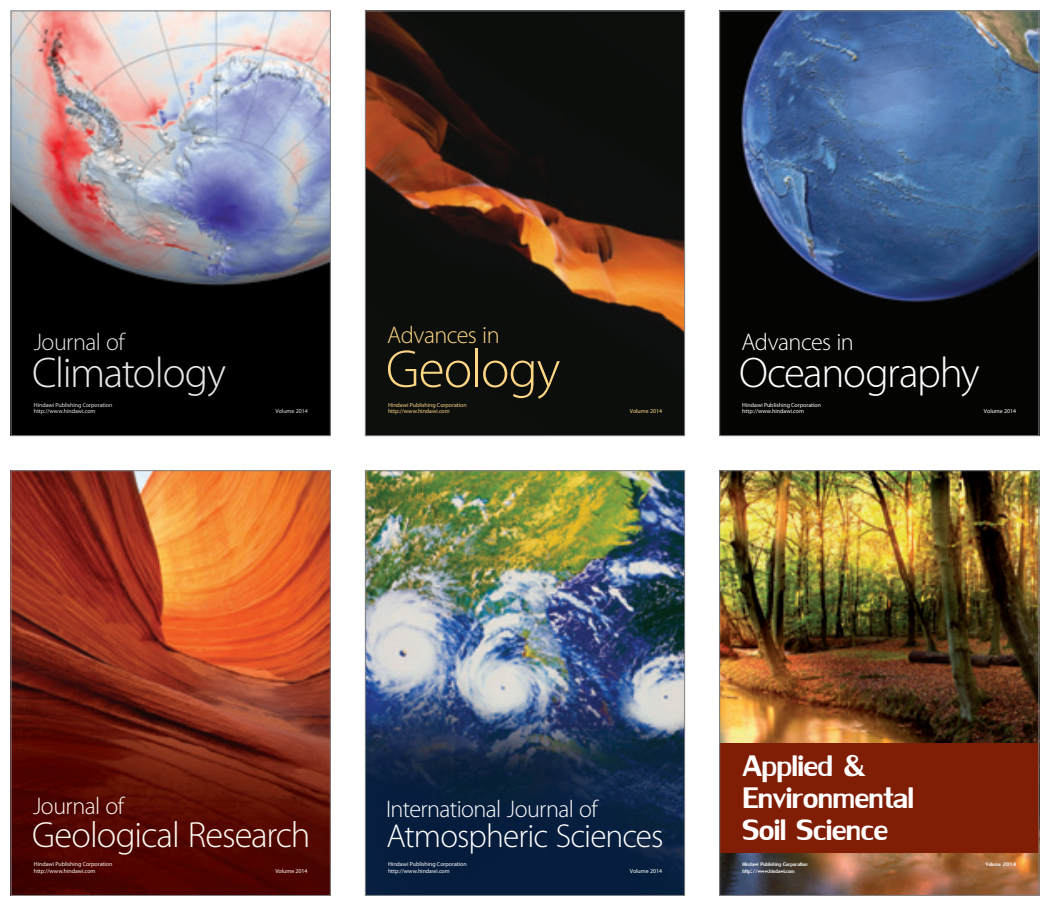
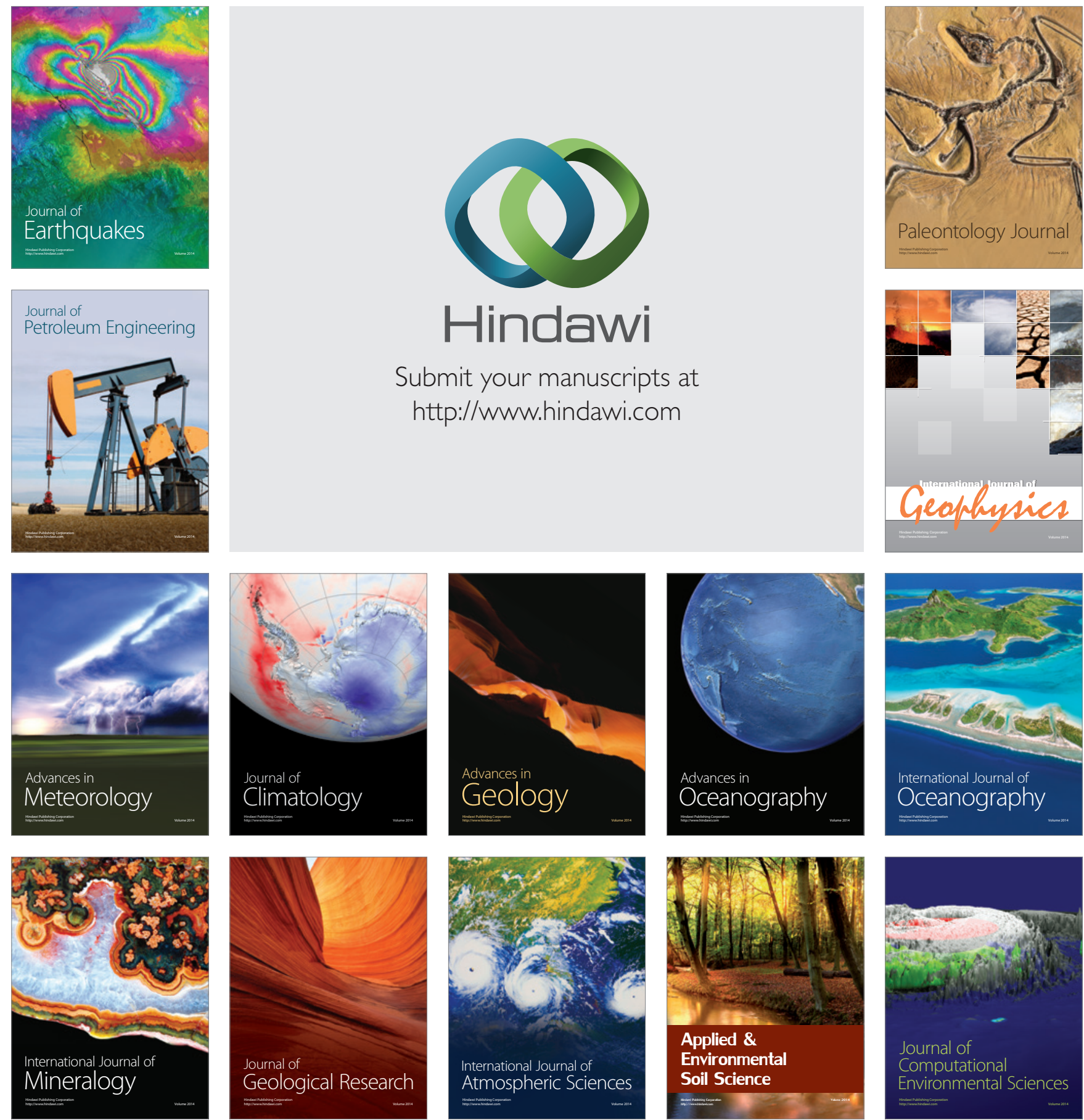